\title{
The utility of post-traumatic skull X-rays
}

\author{
D. F. GORMAN
}

Accident and Emergency Department, Chester Royal Infirmary, Chester, England

\section{SUMMARY}

During two 12-month periods, 12395 accident and emergency department attenders with head injury were collected. Those characteristics which were significantly more common in head-injured patients who had skull fractures on X-ray were identified. These characteristics were: recent alcohol consumption in adults, initial unconsciousness, amnesia of any duration, vomiting, neurological signs, injuries sustained by pedestrians, motorcyclists and cyclists. Such characteristics were then further examined and their power as diagnostic tests for the presence of skull fracture on $\mathrm{X}$-ray was detailed. In individual patients and especially in children, these characteristics were generally of little value in identifying patients with fractures. It was considered that, in the majority of individual patients with head injuries, accurate clinical diagnosis of radiologically apparent fractures was not possible. In view of this and in the light of the known risks in patients with fractures, it was concluded that skull X-rays should continue to be used relatively freely in the management of these patients.

\section{INTRODUCTION}

Following articles by Bell \& Loop (1971) and Roberts \& Shopfner (1972), there has been worldwide interest regarding the place of skull X-ray in the management of patients with head injury. Publications have appeared from Australia (De Campo \& Petty, 1980), Canada (Harwood-Nash et al., 1971; Cordon, 1981), Denmark (Anderson, 1978), Finland (Tunturi et al., 1982), the United Kingdom (Boulis et al., 1978; Eyes \& Evans, 1978; de Lacey et al., 1980; Jennett, 1980; Royal College of Radiologists, 1980, 1981, 1983; Gibson, 1983) and the United States (de Smet et al., 1979; Phillips, 1979; Cummins et al., 1980; Masters, 1980; Leonidas et al., 1982; Larsen \& Koziol, 1979). Such articles have provoked both a lively correspondence and editorial comment, but

Correspondence: D. F. Gorman, Accident and Emergency Department, Warrington District General Hospital, Lovely Lane, Warrington WA5 $1 Q$, England 
revealed a dichotomy of opinion. On the one hand, radiologists believe that skull X-ray $\frac{\mathbb{D}}{\mathrm{S}}$ are over-used in head-injured patients, rarely affect management decisions, rarely show positive findings and are generally wasteful of resources (Bell \& Loop, 1971; Roberts \&. Shopfner, 1972; Eyes \& Evans, 1978; Royal College of Radiologists, 1981; Phillips $\overrightarrow{\nexists \overrightarrow{3}}$ 1979; Masters, 1980). The opposing view, usually expressed by neurosurgeons and accident surgeons, is that plain skull films are indispensable in that they help to identif patients at risk from complications such as intracranial haematoma (Jennett, 1980 Galbraith, 1976; Galbraith, 1973; Mendelow et al., 1983; Briggs et al., 1984) of infection (Miller \& Jennett, 1968; Jennett \& Miller, 1972; Sande et al., 1980, Briggs 1974), and may allow the identification of patients requiring admission who woul $\vec{P}$ otherwise be discharged (Jennett, 1980; Mendelow et al., 1983; Briggs et al., 1984) or $\overrightarrow{\vec{e}}$ conversely, allow the safer discharge of patients who might otherwise be admitte $\mathbb{S}^{\mathrm{S}}$ (Jennett, 1980; Mendelow et al., 1983; Briggs et al., 1984). It has also been suggeste $\Phi$. that half or more of radiologically apparent skull fractures are missed by accident and emergency (A \& E) staff (de Lacey et al., 1980; Gibson, 1983). The present article examines both the usefulness of skull $\mathrm{X}$-rays and the accuracy of radiological diagnosis by $\mathrm{A} \& \mathrm{E}$ staff as well as suggesting which $\mathrm{A} \& \mathrm{E}$ attenders with head injury should be selected for X-ray.

\section{MATERIAL AND METHODS}

All A \& E attenders with head injury during two 12-month periods were collected. 然è earlier study was retrospective and the later study prospective. During both stude periods, head injury was defined according to the presence of one or more of the following:

(1) a history of a blow to the head, with or without a period of unconsciousness of amnesia;

(2) external evidence of injury to the head;

(3) skull X-rays were taken;

(4) head injury instructions were issued.

This definition approximates to rubrics N800-804, N850-854, N870-873, N900 N910, N918-921, N925, N929, N950 and N951 of the International Classification of Diseases (ninth revision). Patients with epistaxis or foreign bodies in the eye, ear or nos were excluded unless they fulfilled the criteria as, with the same proviso, were patients with burns. Patients with facial injuries, including fractures of the mandible, wer\& generally included since they usually fulfilled the definition criteria. All patients with head injury who were brought in dead were excluded as were all patients dying at the. scene, certified there and taken directly to the mortuary. All other attenders who fulfilled the definition criteria were included whether they were X-rayed or not. Fof each attender undergoing skull X-ray, the X-ray report by the $\mathrm{A} \& \mathrm{E}$ doctor wa\$ compared with that by the radiologist.

There was no significant difference between the two study groups in the number definitely having a particular characteristic, for example, knock out and amnesi震 therefore, for statistical analyses, patients for whom there was no record of the presence 
or absence of a particular characteristic were counted as not having that characteristic. Statistical significance was determined using Yates' chi-squared test. In addition, specificities, sensitivities, Youden's indices, relative risks and positive predictive values were calculated.

\section{RESULTS}

During the retrospective study there were 5768 A \& E attenders with head injury and during the prospective study 6685 attenders. Excluding those brought in dead, the total number of patients was 12395 . Skull X-rays were performed in 5484 patients (44\%). A skull fracture or diastasis was present in 206 patients or $3.8 \%$ of those X-rayed. Depressed fractures, mostly compound, occurred in 19 cases (9.2\% of fractures). Pneumocephalus was found in only four patients $(0.03 \%$ of all attenders) but all four had radiologically evident skull fractures. During the prospective study, the presence of clinical signs of skull fractures (CSF leak, bilateral bruising of the upper eyelids etc.) was noted. Such features occurred in 49 patients ( $0.7 \%$ of all attenders) and 28 of these patients had radiologically demonstrated fractures.

The frequency of various characteristics among all attenders and among patients with skull fractures on $\mathrm{X}$-ray is shown in Table 1. Those characteristics which were significantly more common in patients with fractures are further defined in Table 2. Initial unconsciousness occurred in $61 \%$ of cases with fractures but only $6.6 \%$ of all patients initially knocked out had a fracture on X-ray. Similarly, neurological signs were present on initial examination in $43 \%$ of patients with skull fractures but only $14 \%$ of all attenders with signs had a radiologically proven fracture. Initial unconsciousness, amnesia of any duration, vomiting and signs, singly or in any combination, occurred in $147(71 \%)$ of the patients with skull fractures. Thiry-four of the remaining 59 patients with radiologically proven fractures but none of the former characteristics were children, 16 being up to 12-months old. This age difference between those with and those without any or all of these four features was significant. Among all attenders, initial unconsciousness and amnesia became commoner as age increased whereas vomiting was twice as common in children as in adults; neurological signs were slightly commoner in children. Skull fractures on X-ray were significantly less likely to occur in attenders who had been assaulted, however, such cases accounted for $5.3 \%$ of all fractures seen on X-ray.

Acute post-traumatic intracranial haematomas occurred in 11 patients with a total of 14 lesions between them: four extradural haematomas, two patients with both extradural and subdural lesions, two with subdural haematomas alone, one with subdural and intracerebral haematomas, and two with intracerebral haematomas alone. Eight of these patients had a skull fracture on X-ray, two more had fractures clinically and the remaining patient, an 11-year-old boy, had no skull fracture. Thus, there was a highly significant association between radiologically proven fractures and the presence of an acute haematoma. The relative risk of a patient with a skull fracture developing an acute haematoma on X-ray was 164 times that of a patient without a fracture. For a patient with a fracture of the skull diagnosed radiologically and/or clinically, the risk was 296 times greater. 
Table 1 Comparison of the frequency of various characteristics in all A \& $\mathrm{E}$ attenders with head injury a in attenders with skull fractures

\begin{tabular}{|c|c|c|c|}
\hline Characteristic & $\begin{array}{l}\text { All patients } \\
(n=12395) \\
\quad(\%)\end{array}$ & $\begin{array}{l}\text { Patients with } \\
\text { skull fracture } \\
(n=206) \\
(\%)\end{array}$ & 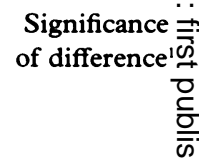 \\
\hline Age: $0-14$ & $42 \cdot 6$ & $43 \cdot 2$ & N.S. \\
\hline $15-64$ & $50 \cdot 9$ & $48 \cdot 5$ & N.S. \\
\hline $65+$ & $6 \cdot 5$ & $8 \cdot 3$ & N.S. \\
\hline Male & $67 \cdot 6$ & $68 \cdot 0$ & N.S. \\
\hline Alcohol (adults) & $10 \cdot 1$ & $17 \cdot 9$ & $* * * * *$ \\
\hline Knocked out & $15 \cdot 2$ & $60 \cdot 7$ & $* * * * *$ \\
\hline Amnesic & $7 \cdot 1$ & $20 \cdot 4$ & $* * * * *$ \\
\hline Vomited & $7 \cdot 0$ & $25 \cdot 7$ & $* * * * *$ \\
\hline Signs & $4 \cdot 9$ & $42 \cdot 7$ & $* * * * *$ \\
\hline Assault & $10 \cdot 8$ & $5 \cdot 3$ & ** \\
\hline Industrial & $5 \cdot 8$ & $6 \cdot 8$ & N.S. \\
\hline Sport & 6.6 & $4 \cdot 4$ & N.S. \\
\hline Fall & $34 \cdot 8$ & $32 \cdot 0$ & N.S. \\
\hline Fall bike & $4 \cdot 8$ & $5 \cdot 8$ & N.S. \\
\hline Pedestrian & $2 \cdot 3$ & $13 \cdot 1$ & $* * * * *$ \\
\hline Cyclist & 1.0 & $5 \cdot 3$ & $* * * * *$ \\
\hline Motorcycle rider & $2 \cdot 5$ & 4.9 & N.S. \\
\hline Pillion passenger & 0.4 & 1.5 & N.S. \\
\hline Car driver & $5 \cdot 5$ & $6 \cdot 8$ & N.S. \\
\hline Front-seat passenger & $2 \cdot 8$ & 1.9 & N.S. $\stackrel{्}{\longrightarrow}$ \\
\hline Rear-seat passenger & $2 \cdot 0$ & $1 \cdot 0$ & N.S. $\bar{Q} \square$ \\
\hline Other cause & $15 \cdot 0$ & $9 \cdot 2$ & ** $\stackrel{?}{?}$ \\
\hline Not recorded & $5 \cdot 7$ & 1.9 & $*$ \\
\hline All motor cyclists & $2 \cdot 9$ & $6 \cdot 3$ & $* * *$ \\
\hline All vehicle occupants & $10 \cdot 3$ & $9 \cdot 7$ & N.S. \\
\hline All R.T.A.’s & $16 \cdot 6$ & $34 \cdot 5$ & $* * * * *$ \\
\hline $\begin{array}{ll}\text { 'N.S.: } & \text { not significant. } \\
* * * & P \text { less than } 0.025 . \\
* * * * * & P \text { less than } 0.0005 .\end{array}$ & $\begin{array}{l}{ }^{*} \quad P \text { less than } 0.05 \\
\text { *** } P \text { less than } 0.01\end{array}$ & & 苟 \\
\hline
\end{tabular}

The skull X-ray reports by the A \& E doctor for those patients with a radiologicalig proven fracture are shown in Table 3. During the retrospective study, two patients wi skull fractures were incorrectly thought to have a fracture of the ipsilateral orbit and 9 prominent vascular marking, respectively. The skull $\mathrm{X}$-rays were considered entire normal by the A \& E medical staff in less than $10 \%$ of patients with skull fractures. N attempt was made to assess the acceptability of the films for diagnostic purposes. $\widetilde{N}$

\section{DISCUSSION}

The clinical diagnosis of a fractured shaft of femur or Colles' fracture is relatively eas $\overrightarrow{y_{0}}$ Similarly, the clinical suspicion of a fracture of the wrist or ankle is often confirmed 
Table 2 Statistical indices for those factors which are significantly more common in patients with skull fractures

\begin{tabular}{|c|c|c|c|c|c|}
\hline Characteristic & Specificity & Sensitivity & $\begin{array}{l}\text { Youden's } \\
\text { index }\end{array}$ & $\begin{array}{l}\text { Relative } \\
\text { risk }\end{array}$ & $\begin{array}{c}\text { Positive } \\
\text { predictive } \\
\text { value }\end{array}$ \\
\hline Alcohol (adults) & 0.99 & $0 \cdot 18$ & $0 \cdot 16$ & 1.97 & 0.03 \\
\hline Knocked out & $0 \cdot 86$ & $0 \cdot 61$ & 0.46 & $9 \cdot 16$ & 0.07 \\
\hline Amnesic & 0.93 & $0 \cdot 20$ & $0 \cdot 13$ & 3.45 & 0.05 \\
\hline Vomited & 0.93 & $0 \cdot 26$ & $0 \cdot 19$ & $4 \cdot 81$ & 0.06 \\
\hline Signs & 0.96 & 0.43 & $0 \cdot 38$ & $16 \cdot 63$ & $0 \cdot 14$ \\
\hline Pedestrian & 0.98 & $0 \cdot 13$ & $0 \cdot 11$ & $7 \cdot 06$ & $0 \cdot 10$ \\
\hline Cyclist & 0.99 & 0.05 & 0.04 & $5 \cdot 82$ & 0.09 \\
\hline Motorcyclist & 0.97 & 0.06 & 0.03 & $2 \cdot 29$ & 0.04 \\
\hline All R.T.A.'s & 0.84 & 0.34 & $0 \cdot 18$ & $2 \cdot 17$ & 0.03 \\
\hline
\end{tabular}

Table 3 Accuracy of skull X-ray report by Accident Unit staff

Accident officers' report

Year

Fracture (\%) Fracture? (\%) Other positive (\%) No bony injury (\%) Totals

\begin{tabular}{lrrrrr}
\hline $1976-1977$ & $76(85)$ & $3(3 \cdot 4)$ & $2(2 \cdot 2)$ & $8(9 \cdot 0)$ & 89 \\
$1979-1980$ & $100(85)$ & $6(5 \cdot 1)$ & - & $11(9 \cdot 4)$ & 117 \\
Totals & $176(85)$ & $9(4 \cdot 4)$ & $2(1 \cdot 0)$ & $19(9 \cdot 2)$ & 206
\end{tabular}

radiologically. The diagnosis of a fracture of the distal phalanx of a finger, the nasal bones or a toe does not determine management, and many would agree that X-rays in such circumstances are redundant. Likewise, the radiological search for an isolated rib fracture is considerably less important than the search for a pneumothorax in the same patient, so that a chest $\mathrm{X}$-ray rather than oblique rib films is, if anything, all that is required. Certain clinical diagnosis of a skull fracture is only possible in $0.7 \%$ of $\mathrm{A} \& \mathrm{E}$ attenders with head injury. Moreover, almost half of such patients with definite skull fractures clinically do not have a fracture on their plain X-rays. In the remaining $99 \%$ of head injury attenders, the presence or absence of a skull fracture cannot be determined clinically, although the likelihood of a fracture being present can be gauged as more or less likely. This overwhelming majority of head injury attenders, in whom the presence or absence of a skull fracture cannot be determined, includes the majority $(76 \%)$ of patients shown to have a skull fracture radiologically. Since demonstrating the presence of a skull fracture is of undoubted significance to clinicians (Briggs, 1974; Briggs et al., 1984; de Lacey et al., 1980; Galbraith, 1973, 1976; Jennett \& Miller, 1972; Jennett, 1980; Larsen \& Koziol, 1979; Mendelow et al., 1983; Miller \& Jennett, 1968; Sande et al., 1980), one must ask how else the fracture can be diagnosed other than radiologically. In fact, it is surprising, in view of the impossibility of making the diagnosis clinically in $99 \%$ of cases, that only about half of all A \& E attenders with head injury undergo skull $\mathrm{X}$-ray examination. Further evidence of the impossibility of making a certain diagnosis 
of skull fracture is provided by the report of the Royal College of Radiologists (1980). 迹 this study, $27 \%$ of skull fractures were not clinically suspected prior to X-ray and one i⿱一⿱㇒⿵冂⿰丨丨寸心 eight of all skull fractures occurred in cases in whom the doctor was clinically certain that no fracture was present. It is not unusual for (experienced) doctors to find a sku何 fracture on X-ray when they had little apparent reason for suspecting such a finding even to X-ray the patient. Such surprises are more likely in children. In one large paediatric series, $39 \%$ of children with a skull fracture on X-ray had either no externa evidence of head injury (28\%) or else such evidence was contralateral (11\%) (Harwood Nash et al., 1971). In another children's series, the authors concluded that there was no correlation between symptoms, physical findings and the likelihood of skull fracture (Boulis et al., 1978), a view shared by Roberts \& Shopfner (1972). In a post-mortem series of selected patients, $20(39 \%)$ of 51 cases with wholly or predominantly unilater fractures did not have corresponding external evidence of injury (Adams et al., 1980 Thus, there is ample evidence that certain clinical diagnosis of the presence or absence of a skull fracture is impossible in the overwhelming majority of individual $\mathrm{A} \& \mathrm{E}$ attenders with head injury. Nevertheless, various reports, including this one, have shown that certain characteristics are significantly more common among groups of patients with skull fractures on X-ray and have grouped these characteristics together as a high-yield list (Bell \& Loop, 1971; Boulis et al., 1978; Cordon, 1981; Cummins et alه 1980; De Campo \& Petty, 1980; de Smet et al., 1979; Masters, 1980; Phillips, 197审 Tunturi et al., 1982). These authors then advocate that only those head injury attenders with one or more of the high-yield characteristics should undergo skull X-ray examination, thereby reducing the number of skull X-rays performed. Howe implementing such lists may lead to up to $61 \%$ of skull fractures being missed Campo \& Petty, 1980). This high failure rate would not be acceptable to cliniciă⿱ indeed, when such lists have been introduced, non-compliance by the clinicians dealing with patients first hand has been high (Cordon, 1981; Cummins et al., 1980; de Smet of al., 1979; Phillips, 1979); $80 \%$ or more of patients X-rayed not fulfilling high-yiel criteria (Phillips, 1979; Cummins et al., 1980). Cummins (1980) investigated the reasons for non-compliance and concluded that these were neither perverse no irrational but that they were highly discretionary, and not attributable to ignorance head injury or the methods used for its evaluation. Failure of high-yield lists to identify fractures was most likely in children (de Smet et al., 1979), a finding confirmed in the present study.

The characteristics identified from the present study as being significantly more common among groups of patients with skull fractures are generally those also identifieg by other workers. However, none of these characteristics were capable of accurately identifying those individuals who did have a fracture on $\mathrm{X}$-ray, i.e. low sensitivity. The poor performance as diagnostic tests was reflected also in their low Youden's inder. Rejecting all A \& E attenders, prior to history-taking and examination, as not having fracture would be surprisingly accurate-98.3\% correct-but 206 patients with fraetures would be left at considerable risk. Sheps \& Schechter (1984) stated that the clinic utility of diagnostic tests is critically determined by the positive and negative predictive values. The positive predictive values of the characteristics referred to above are universally low in the present study (Table 2). Therefore, by this criterion, the characteristics commonly included in high-yield lists also fail as diagnostic tests for the 
presence of skull fracture not even being redeemed by a negative result effectively excluding the presence of a fracture since none had a negative predictive value equal to 1. Also in the present study, one group of patients was significantly less likely to have a skull fracture, i.e. those assaulted, yet nobody would suggest that because of this no assaulted patient should be $\mathrm{X}$-rayed, although this is effectively what a high-yield list would advocate.

Radiologists often imply that because few skull X-rays show the presence of a skull fracture this investigation is of little value (Bell \& Loop, 1971; Boulis et al., 1978; De Campo \& Petty, 1980; de Lacey et al., 1980; Evans, 1977; Eyes \& Evans, 1978; Masters, 1980; Phillips, 1979; Roberts \& Shopfner, 1972; Royal College of Radiologists, 1980, 1981, 1983). However, a low positive yield from an investigation does not necessarily mean that such an investigation is worthless. In the case of skull fractures, there is no practical way in the majority of individual cases of diagnosing the presence or absence of a fracture except radiologically. For the clinician, knowing that a skull fracture is present or absent has important implications (Briggs, 1974; Briggs et al., 1984; Galbraith, 1973, 1976; Jennett, 1980; Jennett \& Miller, 1972; Mendelow et al., 1983; Miller \& Jennett, 1968; Sande et al., 1980).

Another common misconception amongst radiologists is that all A \& $\mathrm{E}$ attenders with head injury have a skull X-ray (Boulis et al., 1978; Evans, 1977; Eyes \& Evans, 1978; Masters, 1980; Phillips, 1979). In the present study, less than half of head injury attenders underwent skull X-ray examination. In Scotland, only $58 \%$ underwent this investigation (Strang et al., 1978) and, in Newcastle, 62\% (Maitra, 1981), the same proportion as in Dumfries (Welch, 1983), whilst in an adult population $65 \%$ were Xrayed (Swann et al., 1980).

It has often been alleged that the skull X-ray appearances all too infrequently affect management decisions (Anderson, 1978; Evans, 1977; Eyes \& Evans, 1978; Masters, 1980; Phillips, 1979; Roberts \& Shopfner, 1972). This allegation is not supported by the authors' findings. For example, in one of the latter studies, five of eight patients with a skull fracture on X-ray had their management altered by the finding of a fracture (Eyes \& Evans, 1978). In another, an unstated number were admitted to hospital solely on the basis of finding a fracture (Roberts \& Shopfner, 1972) and admission in such cases was a management decision. Failure to appreciate that admission for observation is a form of management was also evident in Phillips' study (1979). In this latter study, $76 \%$ of patients with fractures had their management altered by the finding of a fracture. In a further study, it seemed accepted practice that $49 \%$ of patients with skull fractures would be discharged from the A \& E department (Masters, 1980), but such practice would not be acceptable in Britain. This latter study also clearly demonstrated the significant relationship between skull fractures and outcome, despite the authors' conviction that he had demonstrated the absence of any significant relationship. In the present study, 47 patients (23\% of those with fractures) were admitted because of the finding of a fracture on X-ray, 30 of these were children, no fewer than 12 being in the first year of life.

Medico-legal considerations are also often thought to contribute to unnecessary requests for skull X-ray, although the proportion of requests attributed to these reasons is very variable (Bell \& Loop, 1971; Boulis et al., 1978; Cordon, 1981; Cummins, 1980; de Lacey et al., 1980; Eyes \& Evans, 1978; Roberts \& Shopfner, 1972; Royal College of 
Radiologists, 1980), but the only reasons for selecting patients for (skull) X-ray aft injury are medical; if no medical reason exists, there can be no legal reason for an X-ra疋 It behoves doctors to agree the medical indications for a skull $\mathrm{X}$-ray. The recommendâtions as to which patients should be $\mathrm{X}$-rayed should be based on careful consideration the evidence available and agreed by $A \& E$ specialists, who see large numbers of mit head injuries and who accept initial clinical responsibility for these patients.

In the study reported here, radiological diagnosis by A \& E staff was correct in $85 \frac{\overline{9}}{8}$ and in less than $10 \%$ with skull fractures on X-ray were the films considered entire normal by the A \& E staff. Twelve of the 19 patients in the latter group had none of the clinical characteristics: knock out, amnesia, vomiting or signs. Of the two patien $\overrightarrow{\mathbb{B}}$ misdiagnosed radiologically, one had none of these features and the other had on $\overrightarrow{\mathrm{F}}$ vomited. The accuracy of radiological diagnosis displayed here is similar to that in adult series (88\%) (Swann et al., 1980) and much better than in two other series (d Lacey et al., 1980; Gibson, 1983). Sample sizes in the latter two series were small, onf four (de Lacey et al., 1980) and 10 (Gibson, 1983) patients having skull fractures on $X_{-}$ ray, of which, 50 and $60 \%$ were missed, respectively. Generalizations based on these latter two papers are, therefore, not justified.

In view of the cogent reasons for $\mathrm{X}$-raying patients and, in the light of the foregoing discussion, it is suggested that the following groups of head injury attenders shougd have skull X-rays:

(1) all children with a history of or external evidence of injury to the head;

(2) any patient with neurological signs, whether attributed to alcohol or not;

(3) those patients with clinical signs of a skull fracture;

(4) all patients with lacerated wounds of the scalp, in whom penetration is possib

(5) any patient initially knocked out or amnesic;

(6) patients with significant symptoms following a head injury.

In addition, skull X-ray should be considered in head-injured patients not includiad in the above categories but who have:

(a) other injuries warranting admission in their own right;

(b) other conditions by themselves dictating admission.

Applying such indications would mean that about three-quarters of all head inju部 attenders would undergo skull $X$-ray rather than the present $60 \%$.

\section{ACKNOWLEDGEMENTS}

This study forms part of a larger study spread over several years. As such, it would nọ have been possible without the willing cooperation and ready assistance of the medical, nursing and clerical staff in the department, as well as those in medical records. To dil those involved, I offer my sincere thanks. Help and encouragement were also given by the consultants in the other specialities involved and I thank them. Processing of the data by the Mersey Regional Computer Centre was funded through the generosity gुf the Chester District Management Team. 


\section{REFERENCES}

Adams J. H., Graham D. I., Scott G., Parker L. S. \& Doyle D. (1980) Brain damage in fatal non-missile head injury. Fournal of Clinical Pathology 33, 1132-45.

Anderson P. E. (1978) Emergency X-ray of the skull after head injuries. Ugeskr Laeger 140, 1687-91 (English abstract).

Bell R. S. \& Loop M. D.(1971) The utility and futility of radiographic skull examination for trauma. New England fournal of Medicine 284, 236-9.

Boulis Z. F., Dick R. \& Barnes N. R. (1978) Head injuries in children-aetiology, symptoms, physical findings and X-ray wastage. British fournal of Radiology 51, 851-4.

Briggs M. (1974) Traumatic pneumocephalus. British fournal of Surgery 61, 307-12.

Briggs M., Clarke P., Crockard A., Cummins B., Galbraith S., Garfield J., Jeffreys R., Jennett B., Kalbag R., Mendelow A. D., Miller J. D., Price D., Taylor J., Teasdale G. \& Uttley D. (1984) Guidelines for initial management after head injury in adults: suggestions from a group of neurosurgeons. British Medical fournal 288, 983-5.

Cordon I. W. (1981) Skull roentgenography for patients with head trauma: the use of high-yield criteria. Canadian Medical Association Fournal 124, 584-9.

Cummins R. O., Logerfo J. P., Inui T. S. \& Weiss N. S. (1980) High-yield referral criteria for post-traumatic skull roentgenography: response of clinician and accuracy of criteria. fournal of the American Medical Assocation 244, 673-6.

Cummins R. O. (1980) Clinicians reasons for overuse of skull radiographs. American fournal of Roentgenology 135, 549-52.

De Campo J. \& Petty P. G. (1980) How useful is the skull X-ray examination in trauma? Medical fournal of Australia 2, 553-6.

de Lacey G., Guilding A., Wignall B., Reidy J. \& Bradbrook S. (1980) Mild head injuries: a source of excessive radiography? (analysis of a series and review of the literature). Clinical Radiology 31, 457-62.

de Smet A. A., Fryback D. G. \& Thornbury J. R. (1979) A second look at the utility of radiographic skull examination for trauma. American fournal of Roentgenology 132, 95-9.

Evans K. T. (1977) The radiologists dilemma. British fournal of Radiology 50, 299-301.

Eyes B. \& Evans A. F. (1978) Post-traumatic skull radiographs: time for a re-appraisal. Lancet ii, 85-6.

Galbraith S. L. (1973) Age-distribution of extradural haemorrhage without skull fracture. Lancet i, 1217-8.

Galbraith S. (1976) Misdiagnosis and delayed diagnosis in traumatic intracranial haematoma. British Medical fournal 1, 1438-9.

Gibson T. C. (1983) Skull X-rays in minor head injury: a review of their use and interpretation by casualty officers. Scottish Medical fournal 28, 132-7.

Harwood-Nash D. C., Hendrick E. B. \& Hudson A. R. (1971) The significance of skull fractures in children: a study of 1187 patients. Radiology 101, 151-5.

Jennett B. \& Miller J. D. (1972) Infection after depressed fracture of skull: implications for management of non-missile head injuries. Fournal of Neurosurgery 36, 333-9.

Jennett B. (1980) Skull X-rays after recent head injury. Clinical Radiology 31, 463-9.

Larsen K. T. \& Koziol D. F. (1979) High-yield criteria and emergency department skull radiography: two community hospitals experience. Fournal of the American College of Emergency Physicians 8, 393-5.

Leonidas J. C., Ting W., Binkiewicz A., Vaz R., Scott M. \& Pauker S. G. (1982) Mild head trauma in children: when is a roentgenogram necessary? Paediatrics 69, 139-43.

Maitra A. K. (1981) Pattern of care of mild head injuries in Accident and Emergency Department. British fournal of Clinical Practice 35, 385-9.

Masters S. J. (1980) Evaluation of head trauma: efficacy of skull films. American fournal of Roentgenology 135, 539-47.

Mendelow A. D., Teasdale G., Jennett B., Bryden J., Hessett C. \& Murray G. (1983) Risks of intracranial haematoma in head-injured adults. British Medical fournal 287, 1173-6.

Miller J. D. \& Jennett W. B. (1968) Complications of depressed skull fracture. Lancet 2, 991-5.

Phillips L. A. (1979) Comparative evaluation of the effect of a high-yield criteria list upon skull radiography. fournal of the American College of Emergency Physicians 8, 106-9.

Roberts F. \& Shopfner C. E. (1972) Plain skull roentgenograms in children with head trauma. American fournal of Roentgenology 114, 230-40. 
Royal College of Radiologists (1980) A study of the utilisation of skull radiography in nine accident an emergency units in the U.K. Lancet ii, 1234-7.

Royal College of Radiologists (1981) Costs and benefits of skull radiography for head injury. Lancet ii, 791-㫧

Royal College of Radiologists (1983) Patient selection for skull radiography in uncomplicated head injur Lancet i, 115-8.

Sande G. M., Galbraith S. L. \& McLatchie G. (1980) Infection after depressed fracture in the West Scotland. Scottish Medical fournal 25, 227-9.

Sheps S. B. \& Schechter M. T. (1984) The assessment of diagnostic tests: a survey of current medic research. Fournal of the American Medical Association 252, 2418-22.

Strang I., MacMillan R. \& Jennett B. (1978) Head injuries in accident and emergency departments at Scottish hospitals. Injury 10, 154-9.

Swann I. J., MacMillan R. \& Strang I. (1980) Head injuries at an inner city accident and emergen $\vec{\vartheta}$ department. Injury 12, 274-8.

Tunturi T., Nieman R., Patiala H., Rokkanen P., Tammilehto L. \& Turunen M. (1982) Head injuries ara skull radiography: clinical factors predicting a fracture. Injury 13, 478-83.

Welch G. H. (1983) The management of head injuries in a district general hospital. fournal of the Roya College of Surgeons of Edinburgh 28, 8-13. 